DOI: $10.1590 / 1089-6891 v 16 i 219209$

MEDICINA VETERINÁRIA

\title{
LAPAROSCOPIC TECHNIQUE VERSUS OPEN TECHNIQUE IN SWINES ADRENALECTOMY
}

\section{TÉCNICA LAPAROSCÓPICA VERSUS TÉCNICA ABERTA PARA ADRENALECTOMIA EM SUÍNOS}

\author{
José Belarmino da Gama Filho ${ }^{1}$ \\ Danilo Ferreira Rodrigues ${ }^{2}$ \\ Fernanda Figueiredo Mendes ${ }^{2}$ \\ Bruno Lopes Gama ${ }^{3}$ \\ Rejane Bernardes Souza Santos ${ }^{4}$ \\ Leonardo Reis Corrêa ${ }^{5}$ \\ José Renato Junqueira Borges ${ }^{6}$ \\ Luiz Antônio Franco da Silva ${ }^{7}$ \\ Neusa Margarida Paulo ${ }^{7}$ \\ ${ }^{1}$ Médico Veterinário Doutor da Fundação Jardim Zoológico de Brasília, Brasília, DF, Brasil - \\ belargama@gmail.com \\ ${ }^{2}$ Pós-Graduandos da Escola de Veterinária e Zootecnia da Universidade Federal de Goiás, Goiânia, GO, \\ Brasil. \\ ${ }^{3}$ Graduando em Medicina da Faculdade de Medicina da Universidade de Brasília, Brasília, DF, Brasil. \\ ${ }^{4}$ Médica Veterinária do Centro Veterinário Asa Sul, Brasília, DF, Brasil. \\ ${ }^{5}$ Médico Veterinário Mestre do Centro Veterinário Asa Sul, Brasília, DF, Brasil. \\ ${ }^{6}$ Professor Doutor da Universidade de Brasília, Brasília, DF, Brasil. \\ ${ }^{7}$ Professores Doutores da Universidade Federal de Goiás, Goiânia, GO, Brasil.
}

\begin{abstract}
Among the main benefits of laparoscopic adrenalectomy (LA) compared to open adrenalectomy (OA) the rapid recovery of patients with decreased length of stay in hospital can be highlighted. The objective of this study was to compare the open adrenalectomy with laparoscopic adrenalectomy in swine. Thirty-two swine were operated. The animals had been divided into four groups $(n=8)$, one group was submitted to OA and the other to LA, together with its respective control group. Parameters were evaluated regarding operative time, body temperature, hematocrit, postoperative and intraoperative complications and time to deambulation. There was no meaningful difference between operative and deambulation times, even though the latter having been higher in the group submitted to OA. The most frequent intercurrences were in bowel, damage to adrenal vessels and renal hematoma. There were no significant blood losses, and observed hypothermia did not have any clinical impact. Laparoscopy in swine experimental adrenalectomy is a reliable technique that can serve as a reference for the surgical treatment of patients with adrenal diseases with surgical indications in other animal species.
\end{abstract}

Keywords: adrenal glands; animal models; blood supply; laparoscopy. 


\section{Resumo}

Dentre os principais benefícios da adrenalectomia laparoscópica (AL) frente à adrenalectomia aberta (AA) destaca-se a rápida recuperação dos pacientes com diminuição do tempo de internação. $O$ objetivo deste estudo foi comparar a adrenalectomia aberta com a adrenalectomia laparoscópica em suínos. Foram operados 32 suínos, distribuídos em quatro grupos $(n=8)$, sendo um grupo submetido à $\mathrm{AA}$ e outro grupo à $\mathrm{AL}$, com seus respectivos grupos controle. Foram avaliados parâmetros referentes a tempo operatório, temperatura corporal, hematócrito, intercorrências operatórias e tempo de deambulação. Não houve diferença significativa entre os tempos operatórios e de deambulação, apesar deste último ter sido maior no grupo submetido à AA. As intercorrências mais frequentes foram acidentes em alças intestinais, lesões em vasos adrenais e hematoma renal. As perdas sanguíneas não foram significativas, a hipotermia observada não apresentou repercussão clínica. A laparoscopia para adrenalectomia experimental em suínos é uma técnica confiável podendo servir como referência para o tratamento de doenças adrenais com indicações cirúrgicas em outras espécies animais.

Palavras-chave: glândulas supra-renais; irrigação sanguínea; videocirurgia.

Recebido em: 02 julho 2012.

Aceito em: 23 janeiro 2015.

\section{Introduction}

Adrenal diseases are among the main endocrine disorders in pets, mainly dogs and ferrets ${ }^{(1,2)}$, but it has also been reported in cats ${ }^{(3)}$ and horses ${ }^{(4)}$. In humans, laparoscopic adrenalectomy (LA) has been consolidated as a key feature for the treatment of neoplastic diseases, which require surgical treatment, as in cases of non-invasive, under 6-cm tumors, with no evidence of metastases ${ }^{(5)}$. On the other hand, open adrenalectomy (OA) in humans should be considered in cases where tumors are larger than $8 \mathrm{~cm}$, having infiltrative characteristics, signs of metastases, the imaging studies are suggestive of malignancy and in cases where patients have multi secretory tumors or family history of malignant pheochromocytoma. Other indications of OA include adrenal disorders that course with rapid development of virilization, feminization and Cushing's syndrome ${ }^{(6)}$. Despite resistance to the choice of LA, particularly because of the need for technical improvement ${ }^{(7)}$, this method has emerged as the elective intervention method in adrenal glands ${ }^{(8)}$. For animals with severe systemic changes such as uncontrolled bleeding disorders, severe cardiopulmonary disease, basic acid disorders and hypertension LA is contraindicated, as well as in cases of larger tumors than $6 \mathrm{~cm}$ or very vascularized ${ }^{(9)}$.

Some studies showed lower morbidity when comparing LA to $\mathrm{OA}^{(10)}$. Comparative studies relating OA to LA indicate that the operation time is longer in LA, as well as similarities between the rates of postoperative complications ${ }^{(11)}$. In contrast, the main benefits of LA contrasting with OA highlight the rapid recovery of patients, with an average of 2.7 days in $\mathrm{LA}^{(12)}$ and 11 days in $\mathrm{OA}^{(13)}$. It appears that patients undergoing LA have shorter convalescence time when compared to OA and thus need less medication. The most frequent complications of laparoscopic adrenalectomy are related to blood loss, resulting from the vascular variation found in adrenal glands ${ }^{(14)}$.

Studies for providing minimally invasive methods in veterinary medicine are increasing. The possibility of using animal begins to detach from the time when its resources and methods of implementing the research stage and can be produced for many procedures such as liver biopsy ${ }^{(15)}$, 
sexing of exotic animals ${ }^{(16)}$, ovariohysterectomies ${ }^{(17)}$ and colopexies ${ }^{(18)}$. However, when more complex procedures are needed, operative parameters and techniques should have a standardized design and objective definition ${ }^{(19)}$.

The objective of this study was to compare open adrenalectomy with laparoscopic adrenalectomy in swines as an experimental model. Therefore, parameters related to operative time, operative complications, changes in body temperature and time to deambulation were analysed.

\section{Materials and Methods}

The study was approved by the Ethics Committee of the Animal (CEUA) Institute of Biological Sciences, University of Brasilia (No. UnBDOC 32946/2009), and developed at the Center for Teaching and Training Experimental Health Sciences, Federal District and School of Veterinary and Animal Science, Federal University of Goiás. We used 32 healthy, tri-cross, male swines (Sus scrofa domesticus), with $16 \mathrm{~kg}$ average weight, coming a farm properly inspected by the health agency.

The animals were divided into four groups $(\mathrm{n}=8)$ : group $\mathrm{G} 1$ underwent laparotomy with resection of the left adrenal; group G2 (open or false sham treated) was submitted to laparotomic procedure without resection of the adrenal; group G3 was submitted to laparoscopic procedure with resection of the left adrenal; and G4 (laparoscopic or false sham treated) submitted to the laparoscopic procedure without resection of the adrenal. The operative time (OT) for G2 and G4 (falsely treated) were not considered for statistical analysis. To evaluate the possible blood loss, hematocrit was analyzed five days before the surgical procedure and five days after in hematological centrifuge for micro-hematocrit determination. The animals were submitted to food and water fasting for 12 hours. $5 \mathrm{mg} / \mathrm{kg}$ of azaperone intramuscularly (IM) was used as premedication. Extensive shaving of the ventro-lateral abdomen was done, and after 15 minutes anesthesia induction was performed with propofol $5 \mathrm{mg} / \mathrm{kg}$ intravenously (IV) and anesthesia maintenance with isoflurane 3\%. Immediately after, the antisepsis was made with antiseptic solution of $2 \%$ povidone iodine (PVPI) and $0.1 \%$ iodine ethanol.

Left adrenal approach using the open technique in animals in G1 was performed with a para-costal incision of about $15 \mathrm{~cm}$, as described by Park and Gagner ${ }^{(20)}$. This was followed by the section of the external and internal abdominal oblique muscle, with subsequent displacement of left kidney, spleen, intestinal wall and apex of the pancreas (Figure 1A), and dissection of peritoneum and periglandular fat with monopolar thermal cautery. The accessory renal arteries and the aorta branches were connected, while the other vascular structures were etched (Figures 1B and 1C). Etching renal arteries and vein branches was performed en-bloc with 3-0 nylon monofilament (Figure 1D). To end the procedure, the inventory of the surgical site was conducted and the abdomen closed in layers using simple stitches with 3-0 monofilament nylon.

Laparoscopic adrenalectomy technique adopted in animals in $\mathrm{G} 3$ was trans-abdominal, as described by Kollmorgen et al. ${ }^{(19)}$, with a change of position and pressure of $\mathrm{CO}_{2}$, which was set at $10 \mathrm{mmHg}$, as recommended by Sood et al. ${ }^{(21)}$. The animals were restrained in right lateral decubitus, with support on the edge of the right costal arch, promoting elevation of the area of surgical access. Subsequently, the pneumoperitoneum was installed using a small skin incision, retracting the abdominal wall and inserting a Veress needle in the middle third of the caudal margin of the last rib. 
Then, the site was demarcated for the creation of abdominal access portals. The first portal, of 11 $\mathrm{mm}$, for inserting the $10 \mathrm{~mm}$ optical, at a $0^{\circ}$ angle, was created laterally between the ventral midline and the dorsal line. The second one, of $5 \mathrm{~mm}$, was formed in the middle third of the caudal margin of the last rib. The third one, of $11 \mathrm{~mm}$, was installed in the left mesogastric region, and the last one, a portal of $5 \mathrm{~cm}$, in the left epigastric region. Maryland seizure type grippers, a seizure type grasping forceps, a monopolar electrocautery hook, a Mayo endoscopic needle holder, a clipper and a pair of endoscopic Metzembaun scissors were used.

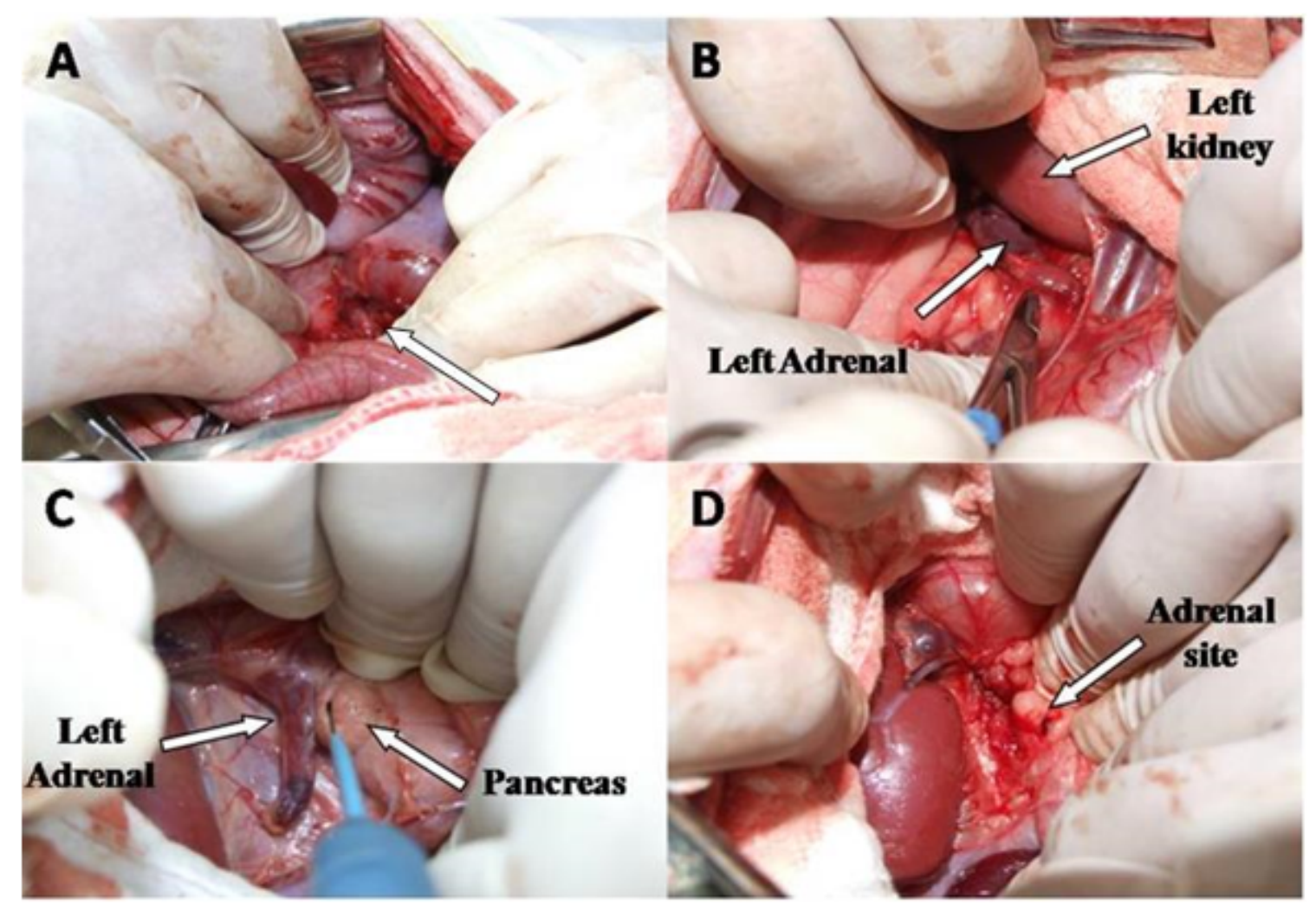

Figure 1: Sequence of the open left adrenalectomy in swines with para-costal approach. A displacement of adjacent organs for glandular identification (arrow); B - identification of the left adrenal, next to the left kidney; $\mathrm{C}$ - dissection with the aid of thermal cautery and a detail of the tail of the pancreas; D - etching of the renal branches and presentation of the adrenal bed.

The approach of the adrenal gland began with the displacement of the left kidney with the aid of seizure type grasping forceps, in order to resect the peritoneum and locate the gland (Figure 2A), followed by the displacement of the intestines, spleen and pancreas, and then by the resection of the gland with the aid of the hook and the Maryland seizure type grippers, from its lateral edge in dorsal and cranial-caudal sense, and the homeostasis of vessels from aortic origin and branches of the celiac and lumbar vessels through thermo cauterization (Figure 2B), isolation as well as double clipping of the renal and vein artery branches were carried out (Fig. 2D). This was followed by inspection of the surgical site and removal of the gland by the 11-mm portal. Two microchips, inflator 9L, 300W xenon light source, instrument and endoscopic devices (Karl Storz, Germany), and thermocautery hook (WEN-São Paulo-SP) were used to process image.

Animals were monitored during the operative procedures; they were assessed on the following variables: operative time (OT), oxyhemoglobin saturation $\left(\mathrm{SpO}_{2}\right)$, heart rate, type of surgical 
complications, temperature, average time to deambulation and mean arterial pressure (MAP). The resulting values of the oxyhemoglobin saturation level, heart rate, temperature and MAP (not invasive) were obtained using a calibrated Multiparametric Vital Sign Monitor (a Hewlett-Packard mod. $78354 \mathrm{c}$, Germany). The records of the operative parameters were performed every ten minutes throughout the OT.

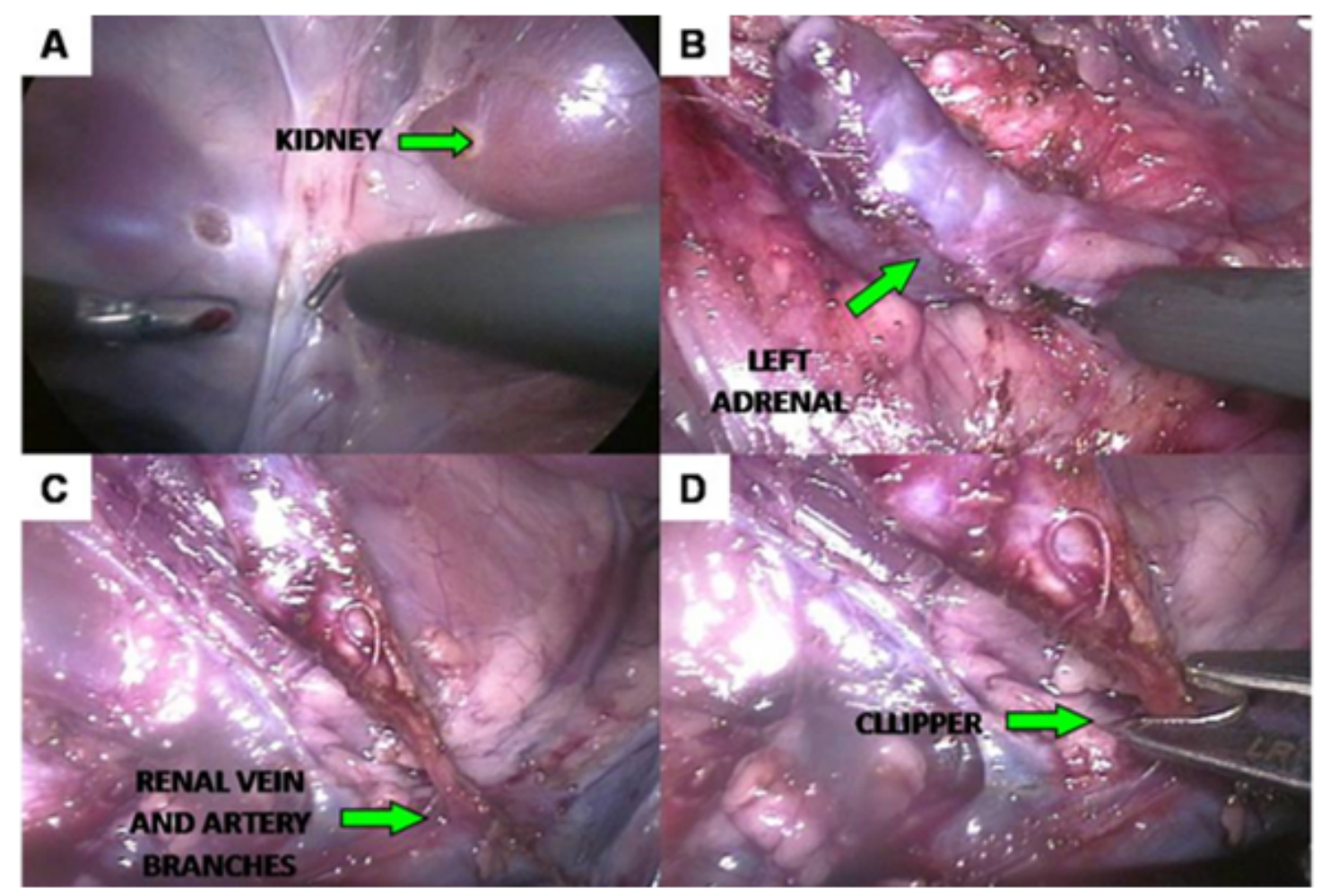

Figure 2: Sequence of laparoscopic adrenalectomy in swines: $\mathrm{A}$ - displacement of organs adjacent to the adrenal; $\mathrm{B}$ - identification and medial/lateral and cranial/caudal dissection; $\mathrm{C}$-identification of the renal artery and vein branches; $\mathrm{D}$ - clipping of the branches of the originating renal artery and vein

Upon completion of the procedures, the animals were transferred to the recovery room after anesthesia and monitored until they showed physiological stability. At this point, deambulation time was recorded (time counted from the end of anesthesia until the animal spontaneously started to walk). After this period the animals were sent to the recovery housing for monitoring drinking water, food intake and treatment of surgical incisions. During the first five days after surgery, they were submitted to antibiotic therapy with Enrofloxacin $5 \mathrm{mg} / \mathrm{kg}$, and postoperative analgesia with Ketoprofen $1 \mathrm{mg} / \mathrm{kg}$, subcutaneously. $1 \mathrm{mg} / \mathrm{kg}$ Ketoprofen was administered for post-operative analgesia, subcutaneously, once daily for five days and daily curatives with Saline $0.9 \%$, and antiseptic with $2 \%$ povidone iodine solution, until the removal of suture stitches, which occurred on the tenth postoperative day.

The surgical techniques were evaluated regarding operative time, body temperature, hematocrit, postoperative and intraoperative complications and time to deambulation. Statistical analysis was performed with descriptive data and Student $\mathrm{T}$ test to evaluate two groups. For the evaluation of 
three or more groups, analysis of variance (ANOVA) was performed, followed by tests of normality Shapiro-Wilk, Levene's test and Tukey test for multiple comparisons and Kruskal-Wallis test. D ata were processed using the statistical analysis program SPSS (Statistical Package for Social Sciences) version 16.0.

\section{Results}

Operative time average of G1 was $66 \min 75 \mathrm{~s}$, while in G3 it was 76 minutes, $14 \mathrm{~min} 03 \mathrm{~s}$ and $16 \mathrm{~min} 62 \mathrm{~s}$ standard deviation, respectively. The median values were $68 \mathrm{~min} 50 \mathrm{~s}$ for $\mathrm{G} 1$ and $75 \mathrm{~min} 50 \mathrm{~s}$ for G3 (Table 1).

Table 1: Mean \pm standard deviation and operative time of adrenalectomy in swine; median in minutes of open and laparoscopic groups

\begin{tabular}{lccc}
\hline Group & Mean \pm SD & Median & Min \\
\hline G1 & $66.75 \pm \mathbf{1 4 . 0 3}$ & 68.50 & 49 \\
G3 & $76.00 \pm 16.62$ & 75.50 & 55 \\
\hline
\end{tabular}

No statistical differences were observed regarding OT in both treated groups when using ShapiroWilk test, with significance level of $\mathrm{P}<0.05$. Five animals of $\mathrm{G} 3$ showed intercurrences in vessels of the adrenal glands, resulting in little blood loss, whereas in G1, only one animal had such complication. Two animals presented lesions in bowels, one animal in G1 and another in G3. In G1, it was due to a cut by the blade of the scalpel and, in G3, it was due to the formation of pneumoperitoneum, by a Veress needle. Both were located in the colon. There were kidney bruises in three animals of G3 (Table 2).

Table 2: Frequency of types of surgical intercurrences in laparoscopic and open adrenalectomy in swine

\begin{tabular}{lcccccc}
\hline \multirow{2}{*}{ Types of intercurrences } & \multicolumn{2}{c}{ G1 } & \multicolumn{2}{c}{ G3 } & \multicolumn{2}{c}{ total } \\
\cline { 2 - 7 } & $\mathbf{n}$ & $\mathbf{0}$ & $\mathbf{n}$ & $\mathbf{\%}$ & $\mathbf{n}$ & $\mathbf{\%}$ \\
\hline Adrenal vessels accidents & 1 & 12.5 & 5 & 62.5 & 6 & 18.8 \\
Bowel injury & 1 & 12.5 & 1 & 12.5 & 2 & 6.3 \\
Renal Hematoma formation & 0 & 0 & 3 & 37.5 & 3 & 9.4 \\
\hline
\end{tabular}

$\mathrm{n}=$ number of animals that presented operative complications

Total processed considering the sum of the four groups

In relation to the hematocrit of the animals on the fifth postoperative day (PO), any significant changes were identified (Table 3 ).

The average BT (body temperature) of the animals of G1 was $36.9^{\circ} \mathrm{C}$, with standard deviation of 0.68 and variance of 0.46 . On the other hand, the average BT of G2 was $37.2{ }^{\circ} \mathrm{C}$, with standard deviation of 0.69 and variance of 0.48 . In G3, the mean BT was $36.5^{\circ} \mathrm{C}$, with standard deviation of 0.38 and variance of 0.14 . In G4 the average BT recorded was $36.8^{\circ} \mathrm{C}$, with standard deviation of 
0.40 and variance of 0.15 . There was no statistical difference among groups $(\mathrm{P}>0.05)$. The medians of studied groups were $37^{\circ} \mathrm{C}$ for $\mathrm{G} 1,37.4{ }^{\circ} \mathrm{C}$ for $\mathrm{G} 2$ and $36.7^{\circ} \mathrm{C}$ for $\mathrm{G} 3$ and G4 (Table 4).

Table 3: Mean values \pm hematocrit standard deviation $\mathrm{n}$ in swine submitted to open and laparoscopic adrenalectomy in relation to sampling times

\begin{tabular}{lccc}
\hline Hematocrit & Group & n & Mean/ standard deviation \\
\hline \multirow{3}{*}{ Five days before surgery } & G1 & 8 & $34.75 \pm 1.66$ \\
& G2 & 8 & $33.50 \pm 2.56$ \\
& G3 & 8 & $33.00 \pm 1.85$ \\
Five days after surgery & G4 & 8 & $32.13 \pm 2.23$ \\
& G1 & 8 & $32.13 \pm 1.35$ \\
& G2 & 8 & $32.38 \pm 4.89$ \\
& G3 & 8 & $31.75 \pm 1.28$ \\
\hline
\end{tabular}

Table 4: Mean values \pm standard deviations and minimum and maximum values of the average BT of swine during the course of OA and LA in degrees Celsius $\left({ }^{\circ} \mathrm{C}\right)$

\begin{tabular}{lccc}
\hline Group & BT Mean \pm standard deviation $\left({ }^{\circ} \mathbf{C}\right)$ & Min & Max \\
\hline G1 & $36.9 \pm 0.67$ & 35.8 & 37.9 \\
G2 & $37.2 \pm 0.69$ & 35.9 & 38.0 \\
G3 & $36.5 \pm 0.37$ & 36.0 & 36.9 \\
G4 & $36.7 \pm 0.39$ & 36.3 & 37.4 \\
\hline
\end{tabular}

TD (time to deambulation) means were 83 minutes for G1, 76min75s for G2, 54min 25s for G3 and $45 \mathrm{~min} 38 \mathrm{~s}$ for G4, with standard deviations of 40 minutes, $12 \mathrm{~min} 82 \mathrm{~s}, 22 \mathrm{~min} 46 \mathrm{~s}$ and $22 \mathrm{~min}$, respectively. The analysis of variance showed a significant difference between the G4 and G1 (P $<0.05$ ) (Figure 3).

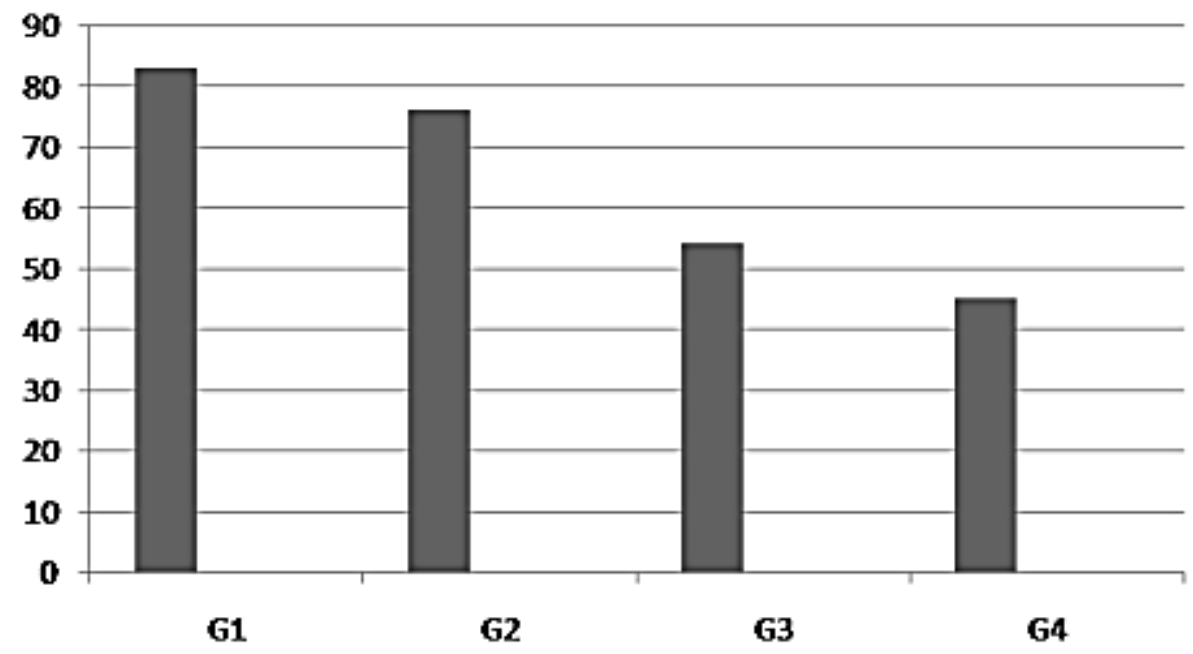

Figure 3: Mean time to deambulation after OA and LA in swine. 


\section{Discussion}

The average OT found in this study was not significantly different among the treated groups. These results are similar to those found by Kollmorgen et al. ${ }^{(19)}$, who carried out a comparative study of open and laparoscopic adrenalectomy in swine. This similarity converges only in the absence of significance, once the means of OT in the study conducted by these authors were $37 \mathrm{~min} 6 \mathrm{~s} \pm 7 \mathrm{~min}$ for LA and 36min6s $\pm 9 \mathrm{~min}$ for OA, while the averages recorded in this study were higher. On the other hand, Park and Gagner ${ }^{(20)}$, in an experimental study of adrenalectomy in swine, found similar results to those found in this work, with average OT to LA of 60 minutes to the procedure in the left adrenal and 90 minutes for the right adrenal, what was attributed to the proximity of the right gland to the vena cava and hepatic vessels, requiring a longer time for execution of dissection maneuvers. In comparative studies of laparoscopic and open adrenalectomy in humans OT is larger, since it relates to operations in adrenal tumors. A non-randomized retrospective study conducted by Mikhail et al. ${ }^{(13)}$ evaluated the results of five patients who underwent LA and seven who underwent OA, and bserved the average OT for the performance of LA was higher than that of OA. As well as the resultsthe results obtained by Yoshimura et al. ${ }^{(22)}$, their study had average time of 376 minutes for LA and 133 minutes for OA. It is a consensus that OT is a disadvantage of laparoscopic adrenalectomy when compared to open adrenalectomy; however, according to Eto et al. ${ }^{(23)}$, as this method becomes more established, there will be a larger number of trained professionals, resulting in the improvement of skills and thus reducing the operative time of laparoscopic adrenalectomy. These considerations are confirmed by Smith et al. ${ }^{(12)}$, who assessed different studies between 1995 and 1997, and found that the OT has been gradually decreasing over the years, with records of 254 minutes in 1995 and 152 minutes in 1998.

The intercurrences in this study were primarily related to the treated groups, G1 and G3. Bowel lesions occurred in one animal in group G1 at the time of the abdominal incision. In group G3, a bowel perforation was caused by a Veress needle at the beginning of the pneumoperitoneum formation. These accidents occur due to the gas buildup in the colon. These occurrences did not result in damage to the procedures, since the shortcomings could be corrected accordingly. Hendrickson ${ }^{(24)}$ reported that, in minimally invasive procedures, the occurrence of accidents at the time of pneumoperitoneum formation is frequent, either by inserting a Veress needle or installing the gates with trocaters. Considerations of injuries caused by the Veress needle were made by Brun et al. ${ }^{(18)}$, who highlighted the spleen as the main organ affected during LA in dogs. Although in the present experiment such lesions have not been observed, the potential risk of using this needle during pneumoperitoneum creation should be taken into consideration.

The bruises formed in the kidney cranial pole of three animals in group G3 were caused by the traction exerted on the body at the time of its displacement to the location and exposure of the surgical site. Other complications presented in this study were vascular accidents, observed in G1 and G3. In both groups, the involved vessels were branches of the renal and aorta arteries, and adrenal veins. As shown in Assalia and Gagner ${ }^{(25)}$, such accidents with subsequent blood loss and need for conversion are common occurrences in LA. Similar results were observed in this study, which showed a higher incidence of vascular accidents in laparoscopic procedures than in the open ones. However, blood loss was not significant, which was confirmed by the maintenance of hematocrit within normal reference values in all animals. 
Overcoming obstacles posed by the diversity of the adrenal vascular represents a great challenge, both in OA and in LA. In this study, the use of optical resources promoted better visibility facilitating vascular homeostasis in laparoscopic procedures, unlike what happened in the open procedure, where the vascular identification of homeostasis was performed with a higher degree of difficulty, resulting in blood loss. However, Parnaby et al. ${ }^{(26)}$, in a retrospective study, demonstrated that human adrenal venous drainage presents great variability, especially in cases of pheochromocytoma. Also, it was highlighted that the operative complexity resulting from this vascular restructuring is solved by the greater accuracy of LA, mainly for the easy vascular identification favored by optical resources available for the implementation of this technique.

During surgical procedures, all studied groups showed a decrease in BT, with an average temperature of $36.9^{\circ} \mathrm{C}$ in $\mathrm{G} 1$ and the highest decrease, $36.5^{\circ} \mathrm{C}$, in G3. These variations, although not showing clinical significance, characterize a normal pattern for swine subjected to experimental procedures $^{(27)}$. BT variations may be related to the type of anesthesia, temperature of the operating room or even the action of $\mathrm{CO}_{2}$ in abdominal cavity during pneumoperitoneum, this may be the justification for the laparoscopic groups to have shown average temperature below the groups submitted to $\mathrm{OA}^{(28)}$.

The TD of the animals in G1 and G3 was similar and can be correlated to the findings of Malm et al. ${ }^{(17)}$, who observed, in a comparative study of bitches submitted to open and laparoscopic ovariohisterectomias, the time for spontaneous locomotion was the same in both groups. In humans, these results have been different, with TD significantly lower in patients undergoing LA, as described by Elashry et al. ${ }^{(29)}$, showing TD of patients undergoing human LA was significantly lower than for OA.

During animal recovery period, parameters regarding water and food ingestion and evolution of surgical wounds were evaluated. We found that two hours after the recovery of deambulation capacity, all of them fed themselves spontaneously. Similar results were found by Malm et al. ${ }^{(17)}$, demonstrating that after the surgical procedures most animals returned to their feeding capacity. The average time to return to spontaneous feeding in patients undergoing human LA and OA may be 24 to 72 hours ${ }^{(23,29)}$. Surgical wounds in this study were monitored daily until the stitches were removed. Wound dehiscence occurred in two animals in G1 and G2. The same pattern of complications in surgical wound was verified by Kollmorgen et al. ${ }^{(19)}$, when evaluating OA in swine. These findings were associated by these authors to large incisions required for the implementation of OA, which may justify the surgical wound dehiscence observed in this study.

\section{Conclusions}

We may conclude laparoscopic adrenalectomy in swine:

- Presented similar operative time to open adrenalectomy;

- Did not promote significant changes in body temperature when compared to the open technique;

- May be related to the increased quantity of operative intercurrences;

- Presented similar time to deambulation as open adrenalectomy;

- Improved recovery of surgical wounds when compared to open adrenalectomy;

- Is a reliable technique that can serve as reference for the surgical treatment of animals with adrenal diseases with surgical indications. 


\section{References}

1. Lee YM, Kang BT, Jung DI, Park C, Kim HJ, Kim JW, Lim CY, Park EH, Park HM. A case of adrenal gland dependent hyperadrenocorticism with mitotane therapy in a Yorkshire terrier dog. Journal of Veterinary Science. 2005;6(4):363-366.

2. Kawasaki T. Comments on treatment of hyperadrenocorticism in ferrets. Journal of Americam Veterinary Medical Association. 2008;233(5):705-706.

3. Behrend E. Update on drugs used to treat endocrine diseases in small animals. Veterinary Clinic of North American Small Animal Practice. 2006;36(5):, p. 1087-1105.

4. McGowan C, Neiger R. Efficacy of trilostane for the treatment of equine Cushing's syndrome. Equine Veterinary Journal. 2003;35(4):414-418.

5. Sturgeon C, Kebebew E. Laparoscopic adrenalectomy for malignancy. Surgical Clinics of North America. 2004;84(3):755-774.

6. Suzuki H. Laparoscopic adrenalectomy for adrenal carcinoma and metastases. Current Opinion In Urology. 2006;16(2):47-53.

7. Naya Y, Suzuki H, Komiya A, Nagata M, Tobe T, Ueda T, Ichikawa T, Igarashi T, Yamaguchi K, Ito H. Laparoscopic adrenalectomy in patients with large adrenal tumors. International Journal of Urology. 2005;12(2):134-139.

8. Lezoche E, Guerrieri M, Crosta F, Lezoche G, Baldarelli M, Campagnacci R. Flank approach versus anterior sub-mesocolic access in left laparoscopic adrenalectomy: a prospective randomized study. Surgical Endoscopy and other Interventional Techniques. 2008;22(11):2373-2378.

9. Mayhew PD. Advanced laparoscopic procedures (hepatobiliary, endocrine) in dogs and cats. Veterinary Clinics of North America: Small Animal Practice. 2009;39:925-939.

10. Corcione F, Miranda L, Marzano E, Capasso P, Cuccurullo D, Settembre A, Pirozzi F. Laparoscopic adrenalectomy for malignant neoplasm - Our experience in 15 cases. Surgical Endoscopy and Other Interventional Techniques. 2005;19(6):841-844.

11. Wells S, Merke D, Cutler GJ, Norton J, Lacroix A. Therapeutic controversy: The role of laparoscopic surgery in adrenal disease. Journal of clinical endocrinology and metabolism. 1998;83(9):3041-3049.

12. Smith C, Weber C, Amerson J. Laparoscopic adrenalectomy: New gold standard. World Journal of Surgery. 1999;3(4):389-396.

13. Mikhail A, Tolhurst S, Orvieto M, Stockton B, Zorn K, Weiss R, Kaplan EL, Shalhav AL. Open versus laparoscopic simultaneous bilateral adrenalectomy. Urology. 2006;67(4):693-696.

14. Tiraboschi RB, Domingos ALA, Reis RB, Bovo TB, Suaid HJ, Cologna AJ, Martins ACP. Adrenalectomia laparoscópica: análise de 11 pacientes. Acta Cirúrgica Brasileira. 2003;18(s5):41-42.

15. Barnes RF, Greenfield CL, Schaeffer DJ, Landolfi J, Andrews J. Comparison of biopsy samples obtained using standard endoscopic instruments and the harmonic scalpel during laparoscopic and laparoscopicassisted surgery in normal dogs. Veterinary Surgery. 2006;35(3):243-251.

16. Hernandez-Divers SJ, Stahl SJ, Farrell R. An endoscopic method for identifying sex of hatchling Chinese box turtles and comparison of general versus local anesthesia for coelioscopy. Journal of Americam Veterinary Medical Association. 2009;234(6):800-804. 
17. Malm C, Savassi-Rocha PR, Gheller VA, Oliveira HP, Lamounier R, Foltynek V. Ovário-histerectomia: estudo experimental comparativo entre as abordagens laparoscópica e aberta na espécie canina. II- Evolução clínica pós-operatória. Arquivo Brasileiro de Medicina Veterinária e Zootecnia. 2005;57(S2):162-172.

18. Brun MV, Pippi NL, Beck CAC, Contesini EA, Stedile R, Bonfada AT, Columé LM, Gomes K, .; Vieira Junior ARP, Silva TF. Colopexia incisional por celiotomia ou transparietal auxiliada por laparoscopia em cães. Ciência Rural. 2004;34(3):829-837.

19. Kollmorgen CF, Thompson GB, Grant CS, Van Heerden JA, Byrne J, Davies ET, Donohue JH, Ilstrup DM, Young WF. Laparoscopic versus open posterior adrenalectomy: Comparison of acute-phase response and wound healing in the cushingoid porcine model. World Journal of Surgery. 1998;22(6):613-620.

20. Park A, Gagner M. A porcine model for laparoscopic adrenalectomy. Surgical Endoscopy-Ultrasound and Interventional Techniques. 1995;9(7):807-810.

21. Sood J, Jayaraman L, Kumra VP, Chowbey PK. Laparoscopic approach to pheochromocytoma: Is a lower intraabdominal pressure helpful? Anesthesia and Analgesia. 2006;102(2):637-641.

22. Yoshimura K, Yoshioka T, Miyake O, Matsumiya K, Miki T, Okuyama A. Comparison of clinical outcomes of laparoscopic and conventional open adrenalectomy. Journal of Endourology. 1998;12(6):555559.

23. Eto M, Harano M, Koga H, Tanaka M, Naito S. Clinical outcomes and learning curve of a laparoscopic adrenalectomy in 103 consecutive cases at a single institute. International Journal of Urology. 2006;13(6):671-676.

24. Hendrickson D. Complications of laparoscopic surgery. Veterinay Clinic of North Americam Small Animal Practice. 2008;24(3):557-571.

25. Assalia A, Gagner M. Laparoscopic adrenalectomy. British Journal of Surgery. 2004;91(10):1259-1274.

26. Parnaby C, Galbraith NO, Dwyer PJ. Experience in Identifying the Venous Drainage of the Adrenal Gland During Laparoscopic Adrenalectomy. Clinical Anatomy. 2008;21(7):660-665.

27. Swindle MM. Swine in the Laboratory, Surgery, Anesthesia, Imaging, and Experimental technique. 2nd ed. New York: Taylor \& Francis; 2007. 450 p.

28. Diemunsch P, Becmeum F, Meyer P. Retroperitoneoscopy versus laparoscopy in piglets: ventilatory and thermic repercussions. Journal of Pediatric Surgery. 1999;34(10):1514-1517.

29. Elashry O, Clayman R, Soble J, McDougall E. Laparoscopic adrenalectomy for solitary metachronous contralateral adrenal metastasis from renal cell carcinoma. Journal of Urology. 1997;157(4):1217-1222. 